\title{
Modeling of the atmospheric response to a strong decrease of the solar activity
}

\author{
Eugene V. Rozanov ${ }^{1,2}$, Tatiana A. Egorova ${ }^{1}$, Alexander I. Shapiro ${ }^{1}$ \\ and Werner K. Schmutz ${ }^{1}$ \\ ${ }^{1}$ Physikalisch-Meteorologisches Observatorium, World Radiation Center \\ Dorfstrasse 33, CH-7260, Davos, Switzerland \\ email: t.egorova@pmodwrc.ch \\ ${ }^{2}$ Institute for Atmospheric and Climate Science, ETH Zurich, \\ CH-8092, Zurich, Switzerland \\ email: e.rozanov@pmodwrc.ch
}

\begin{abstract}
We estimate the consequences of a potential strong decrease of the solar activity using the model simulations of the future driven by pure anthropogenic forcing as well as its combination with different solar activity related factors: total solar irradiance, spectral solar irradiance, energetic electron precipitation, solar protons and galactic cosmic rays. The comparison of the model simulations shows that introduced strong decrease of solar activity can lead to some delay of the ozone recovery and partially compensate greenhouse warming acting in the direction opposite to anthropogenic effects. The model results also show that all considered solar forcings are important in different atmospheric layers and geographical regions. However, in the global scale the solar irradiance variability can be considered as the most important solar forcing. The obtained results constitute probably the upper limit of the possible solar influence. Development of the better constrained set of future solar forcings is necessary to address the problem of future climate and ozone layer with more confidence.
\end{abstract}

Keywords. Climate, ozone, solar irradiance, energetic particles

\section{Introduction}

The warming of the Earth's climate due to anthropogenic greenhouse gases is evident and can become dangerous for mankind in the nearest future (IPCC 2007). The ozone layer was endangered by the anthropogenic emission of chlorine and bromine containing species but is expected to fully recover in the middle of the $21^{\text {st }}$ century due to the limitations introduced by Montreal protocol and its amendments (WMO 2011). On the other hand the current unusually long solar minimum hints to gradual decrease of the solar activity in the future similar to the Dalton minimum of the solar activity (Abreu et al. 2008; Lockwood et al. 2009). What are the implications of this would-be decrease of solar activity for future climate and ozone layer changes? Should we expect any compensation or enhancement of the anthropogenic effects on the atmosphere in the future? This question can be addressed only if we take into account all relevant direct effects of anthropogenic and solar forcing as well as complex feedbacks between different atmospheric processes (Gray et al. 2010). An expected decline of the solar activity will be accompanied by a decrease of the both total solar irradiance (TSI) and spectral solar irradiance (SSI) leading directly to the global cooling, ozone depletion and cooling in the tropical stratosphere followed by a deceleration of the polar night jets and cooler winters over northern land masses (Egorova et al. 2004, Gray et al. 2010). The significance of these effects depends on the magnitude of the applied solar irradiance forcing. The published estimates of the TSI change from Maunder minimum to present are highly uncertain and cover the range 
from 0.5 to $5 \mathrm{~W} / \mathrm{m}^{2}$ (Gray et al. 2010; Feulner 2011) depending on the treatment of secular changes in quiet Sun contribution (e.g., Shapiro et al. 2011; Schrijver et al. 2011). The simulations of the past climate change driven by different TSI reconstructions (e.g., Stott et al. 2003; Feulner 2011) have shown that the application of larger solar forcing is more promising to understand the unexplained global warming in the first half of $20^{\text {th }}$ century (IPCC 2007). The decrease of the solar activity can also change the pattern of energetic particle precipitation. The expected decline of the solar magnetic activity will lead to less intensive deflection of galactic cosmic rays (Barnard et al. 2011) followed by higher ionization rates in the lower atmosphere. A weak solar magnetic activity in the future will not be favorable for coronal mass ejections leading to substantial decrease of powerful solar proton events (Barnard et al. 2011). Substantial decrease of solar wind pressure followed by weaker geomagnetic activity can be also expected if we apply observed correlation between solar magnetic activity and different geomagnetic indexes. Therefore, the effects of solar irradiance can be partially compensated by an expected decrease of the geomagnetic activity leading to less intensive production of nitrogen and hydrogen oxides followed by less intensive ozone destruction and relative warming inside polar vortices (Rozanov et al. 2005; Semeniuk et al. 2011). On the other hand an increase of galactic cosmic rays flux will facilitate ozone destruction and cooling in the polar lower winter stratosphere leading to opposite effects, i.e. to an acceleration of the polar night jets and warmer winters over Europe (Calisto et al. 2011; Semeniuk et al. 2011). The multitude of factors affecting climate requires the application of proper models, which are able to treat different anthropogenic and solar related forcing mechanism and atmospheric feedbacks. Therefore, in order to understand the resulting changes in the atmosphere we apply the chemistry-climate model SOCOL in time-slice mode driven by anthropogenic and solar forcing. In the following sections we describe the model, the set-up of performed experiments and discuss the results.

\section{Model description and experimental set-up}

The CCM SOCOL consists of the global circulation model MA-ECHAM4 and the chemistry-transport model MEZON. MA-ECHAM4 (Manzini et al. 1997) is a spectral model with T30 horizontal truncation resulting in a grid spacing of about 3.75; in the vertical direction the model has 39 levels in a hybrid sigma-pressure coordinate system spanning the model atmosphere from the surface to $0.01 \mathrm{hPa}$. The chemical-transport part MEZON (Egorova et al. 2003) exploits the same vertical and horizontal resolution and treats 41 chemical species of the oxygen, hydrogen, nitrogen, carbon, chlorine and bromine groups, which are coupled by 140 gas-phase reactions, 46 photolysis reactions and 16 heterogeneous reactions in/on aqueous sulfuric acid aerosols, water ice and nitric acid trihydrate (NAT). The solar irradiance variability represented in the model is accounted in the radiation and photochemical modules to calculate the response of the energy budget, heating rates and photolysis frequencies (Egorova et al. 2004). The original version of the CCM SOCOL was described by Egorova et al. (2005). Evaluation of the CCM SOCOL (Egorova et al. 2005; Eyring et al. 2007 ) revealed model deficiencies in the chemical-transport part and led to the development of the CCM SOCOL v2.0. A comprehensive description of the CCM SOCOL v2.0 is presented by Schraner et al. (2008). CCM SOCOL v2.0 participated in the SPARC CCMVal-2 intercomparison campaign (SPARC CCMVal 2010) and showed substantial improvement of transport and chemical diagnostics; however some shortcomings in the simulation of gas transport still remains. This version also includes additional source of nitrogen and hydrogen oxides due to ionization of the neutrals in the atmosphere by different precipitating energetic 
particles. The ionization rates due to the Galactic Cosmic Rays (GCR) have been parameterized using the recently developed CRAC:CRII (Cosmic Ray induced Cascade: Application for Cosmic Ray Induced Ionization) model extended toward the upper atmosphere (Usoskin et al. 2010). The model is based on a Monte-Carlo simulation of the atmospheric cascade and reproduces the observed data within $10 \%$ accuracy in the troposphere and lower stratosphere (Usoskin et al. 2010). The results of the CRAC:CRII model have been parameterized (Usoskin \& Kovaltsov 2006) to give ion pair production rate as a function of the air pressure, geomagnetic cutoff rigidity and solar modulation potential (SMP).

Table 1. Description of the boundary conditions for the performed model experiments.

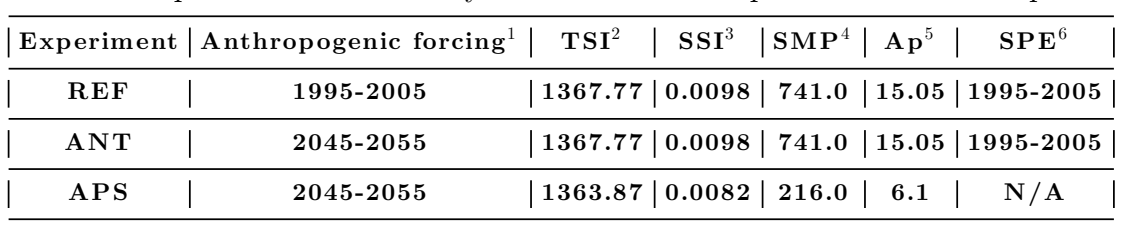

Notes:

${ }^{1}$ Anthropogenic forcing includes greenhouse gases, ozone destroying substances, $\mathrm{CO}_{\text {and }} \mathrm{NO}_{x}$ emissions.

${ }^{2}$ Total solar irradiance (TSI) is in W/m $/ \mathrm{m}^{2}$. ${ }^{3}$ SSI stands for spectral solar irradiance at $205 \mathrm{~nm}$ in $\left(\mathrm{W} / \mathrm{m}^{2} / \mathrm{nm}\right)$.

${ }^{4}$ Solar modulation potential (SMP) is in MV. ${ }^{5} \mathrm{Ap}$ is geomagnetic index. ${ }^{6}$ SPE is averaged intensity of solar proton events.

The ionization rates due to solar proton events (SPE) have to be prescribed. For the satellite era (1963 to 2008) we applied daily averaged ionization rates as functions of pressure between $888 \mathrm{hPa}$ and $8^{*} 10^{-5} \mathrm{hPa}$ (Jackman et al. 2008). The ionization rates were introduced to the model over the polar cap from $60^{\circ}$ to $90^{\circ}$ geomagnetic latitudes. The area of ionization by high energy (more than $10 \mathrm{Mev)}$ protons is located well inside our model domain and their effects should be properly accounted for. The representation of energetic electron effects is more complicated task, because their energy deposition occurs mainly outside our model domain (i.e., above $80 \mathrm{~km}$ ). Therefore, we have parameterized the influx of $\mathrm{NO}_{x}$ produced by energetic electrons above the model top proposed by Baumgaertner et al. (2009) on the basis of the empirical relation with geomagnetic Ap index using their "average excess" $\mathrm{NO}_{x}$ mode. The effect of the energetic electrons on the mesosphere and stratosphere is confined to the polar vortex. Therefore minimum absolute latitude of $55^{\circ}$ has been used, i.e. the products of the ionization by energetic electrons can enter our model domain only over the high latitudes. Further downward propagation of ionization products depends on the presence of polar vortices and appropriate vertical transport, which guarantees that the ionization products properly affect lower mesosphere and stratosphere. The applied parameterization does not include high (more than $50 \mathrm{KeV}$ ) energy electrons which deposit their energy below $80 \mathrm{~km}$. The lack of this process in our model can be justified by smaller contribution of high energy electron precipitation events to the total $\mathrm{NO}_{x}$ production by particles (Sinnhuber et al. 2011) and the absence of proper parameterization. The GCR and SPE ionization rates cannot be directly used in CCM SOCOL which has no explicit treatment of ion chemistry, therefore it is necessary to convert the ionization into the $\mathrm{NO}_{x}$ and $\mathrm{HOx}$ production rates. Following Porter et al. (1976), we assumed that $1.25 \mathrm{NO}_{x}$ molecules are produced per ion pair, and $45 \%$ of this $\mathrm{NO}_{x}$ production is assumed to yield ground state atomic nitrogen, while $55 \%$ is assumed to go into $\mathrm{N}\left({ }^{2} \mathrm{D}\right)$ with instantaneous conversion to NO. The production of HOx has been studied by Solomon et al. (1981) with a 1-D time-dependent model of neutral and ion chemistry. They parameterized the number of odd hydrogen particles produced per ion pair as a function of altitude and ionization 
for daytime, polar summer conditions of temperature, air density and solar zenith angle. We implement these parameterizations in the CCM SOCOL to take into account the production of $\mathrm{NO}_{x}$ and $\mathrm{HOx}$ induced by GCR and SPE from the ground up to $0.01 \mathrm{hPa}$ level. The errors associated with this approach are within 10-20\% (Egorova et al. 2011) which is comparable with the accuracy of ionization rate calculations. For this study, we have carried out three 20-year long runs of CCM SOCOL v2.0 in time slice mode (see Table 1). The reference run (REF) has been driven by boundary conditions for the source gases, aerosol loading, solar irradiance, sea surface temperatures and sea ice concentration identical to the CCMVal-2 experiments (Morgenstern et al. 2010) representing the climatology around year 2000. The same procedure was applied for the solar modulation potential (proxy for GCR), ionization rates by SPE and Ap index (proxy for low energy electrons). For the second run (ANT) we applied the boundary condition identical to CCMVal-2 REF-B2 experiments (Morgenstern et al. 2010) representing the climatology around year 2050 keeping the solar activity related forcing applied for reference simulation. This run represents the future atmospheric state due to anthropogenic forcing only. For the third run (APS) we applied anthropogenic forcing identical to ANT run, but the solar forcing was prescribed for the case of expected strong decrease of the solar activity similar to the Dalton minimum. All solar related forcing was taken as an average over the Dalton minimum period. For the solar total and spectral solar irradiance (TSI and SSI) we have used the latest reconstruction presented by Shapiro et al. (2011). The solar modulation potential for the Dalton minimum was taken from Steinhilber et al. (2010). The frequency of the SPE was set to zero according to strong solar minimum case of Barnard et al. (2011). The geomagnetic Ap index values for the Dalton minimum was set according to Steinhilber (2011, private communications). The first 10 years of all runs are considered as a spin-up time which is necessary for the adaptation to the new boundary conditions and reaching quasi-equilibrium state. In the next sections we analyze the results obtained from the last 10-years of all model experiments. The comparison of the 10-mean climatology allows estimating the potential contribution of the solar forcing to the future climate change and statistical significance of the obtained results.

\section{Results}

Annual and zonal mean difference of total odd nitrogen $\left(\mathrm{NO}_{y}\right)$ in the future relative to present for ANT and APS runs is illustrated in Fig. 1. The anthropogenic changes of $\mathrm{NO}_{y}$ are not very large. The project decrease of $\mathrm{NO}_{x}$ emissions (IPCC 2007) leads to the $\mathrm{NO}_{y}$ decrease in the northern lower troposphere. Slight $\mathrm{NO}_{y}$ increase in the stratosphere is the result of gradually increasing anthropogenic production of $\mathrm{N}_{2} \mathrm{O}$ (the source gas for $\mathrm{NO}_{y}$ ). Negative tendencies in the tropical lower stratosphere and polar mesosphere are caused by relative deceleration of the meridional circulation in the future (SPARC CCMVal 2010, chapter 4). The application of the solar forcing substantially changes the results. Introduced decrease of Ap index leads to lower production of $\mathrm{NO}_{x}$ by precipitating electrons and significant decrease of $\mathrm{NO}_{y}$ in the mesosphere/upper stratosphere. As expected (Semeniuk et al. 2011) this effect is more pronounced in the polar areas leading to $\mathrm{NO}_{y}$ decrease by up to $80 \%$ in the upper mesosphere and up to $20 \%$ in the upper stratosphere. The applied decrease of the solar UV irradiance results in slower NO photolysis and suppressed destruction of $\mathrm{NO}_{y}$ via cannibalistic reaction $\left(\mathrm{N}+\mathrm{NO}=\mathrm{N}_{2}+\mathrm{O}\right)$ leading to enhancement of $\mathrm{NO}_{y}$ in the extra-polar stratosphere. Enhanced ionization by GCR leads to additional production of $\mathrm{NO}_{y}$ below $20 \mathrm{~km}$ more pronounced in relatively clean southern troposphere. These results are consistent with the estimates of $\mathrm{NO}_{y}$ response to energetic electron precipitation and GCR published by Semeniuk et al. (2011) 

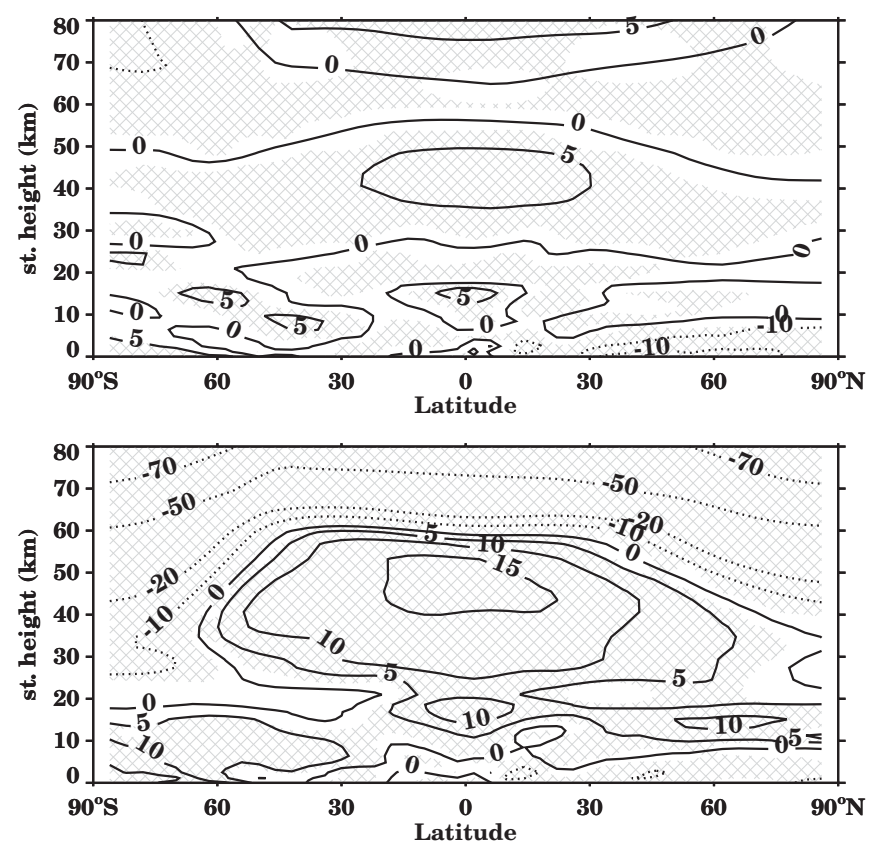

Figure 1. Annual and zonal mean difference (\%) of $\mathrm{NO}_{y}$ in the future relative to present for ANT (anthropogenic forcing, upper panel) and APS (anthropogenic and solar forcing, lower panel) runs. Hatching represent the areas where the statistical significance exceed $90 \%$ level.

and Calisto et al. (2011) and shows that the solar forcing can plays leading role in the future evolution of $\mathrm{NO}_{y}$. Annual and zonal mean difference of ozone in the future relative to present for ANT and APS runs is shown in Fig. 2. The anthropogenic effects on ozone consist of significant ozone increase in the troposphere caused by the enhancement of ozone precursors (i.e., carbon monoxide) and in the lower and upper stratosphere caused by substantial decline of the halogen loading in the future regulated by the Montreal protocol and its amendments (WMO 2011). The later effect is particularly visible in the southern lower stratosphere, where the ozone hole is not so deep in the considered year 2050. The ozone decrease in the tropical lower stratosphere reflects an increase of meridional circulation in the warmer climate (SPARC CCMVal 2010). The decrease of the ozone in the mesosphere can be attributed to the enhancement of the $\mathrm{HO}_{x}$ production caused by the increase of the stratospheric water vapor (SPARC CCMVal 2010). The application of the solar forcing changes the situation dramatically only in the polar mesosphere, where the decrease of $\mathrm{NO}_{y}$ (see Fig. 1) suppresses ozone depletion by catalytical oxidation. In the rest of the atmosphere the solar forcing tends to compete with anthropogenic. Global cooling due to decrease of TSI leads to deceleration of meridional circulation and partial compensation of the ozone depletion is the tropical lower stratosphere. In the middle and upper stratosphere the decrease of solar UV irradiance leads to less intensive ozone production and some compensation of the halogen loading effects. More intensive $\mathrm{NO}_{y}$ production in the troposphere due to GCR causes some compensation of the anthropogenic ozone increase in the upper troposphere. Thus, we can see that the applied solar forcing works in the direction opposite to anthropogenic effects.

Fig. 3 shows the contribution of the solar activity changes to the future total column ozone calculated as a difference between the results of APS and ANT runs. The anthropogenic influence results in ubiquitous increase of the total column ozone in the year 

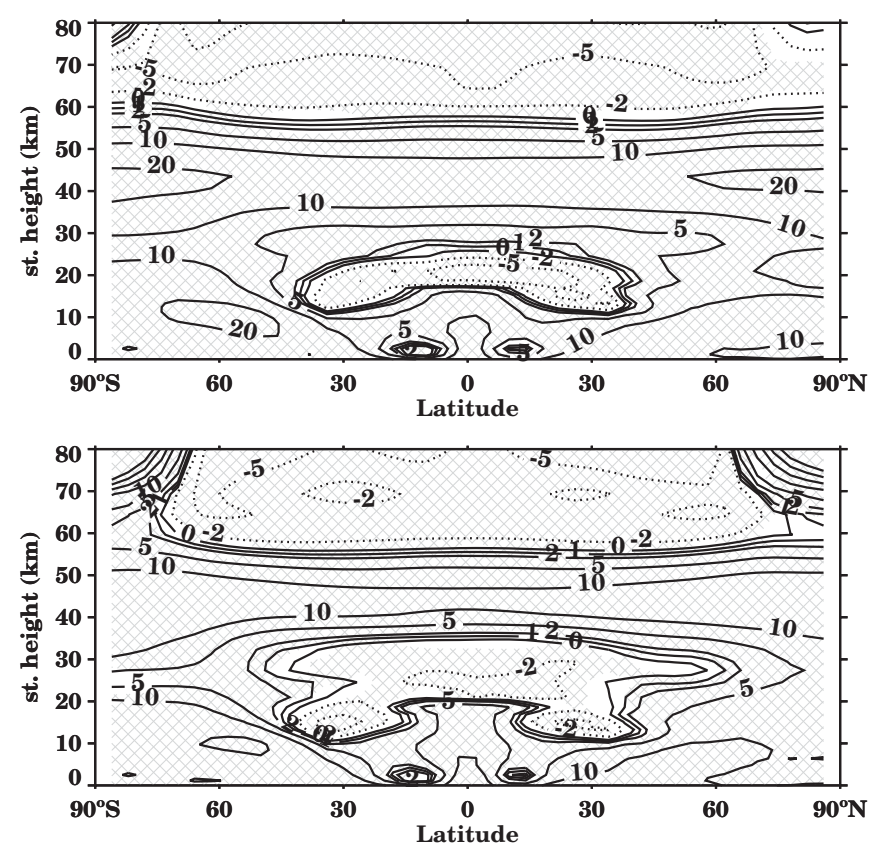

Figure 2. Annual and zonal mean difference (\%) of ozone in the future relative to present for ANT (anthropogenic forcing, upper panel) and APS (anthropogenic and solar forcing, lower panel) runs. Hatching represent the areas where the statistical significance exceed $90 \%$ level.

2050 compare to present day (not shown). This increase is the most pronounced in the polar regions reaching $70 \mathrm{DU}$ during late spring time, but is also statistically significant over the middle and tropical latitudes. These results are in a good agreement with multi-model assessment (SPARC CCMVal 2010). The influence of solar related forcing works in the direction opposite to anthropogenic effects leading to the total ozone depletion in global scale. The solar influence is the most important outside of the polar area leading to substantial compensation of the anthropogenic influence. Over the high latitudes solar influence is marginally significant, but even in this case it can compensate about $30-40 \%$ of anthropogenically induced total ozone recovery. Annual and zonal mean

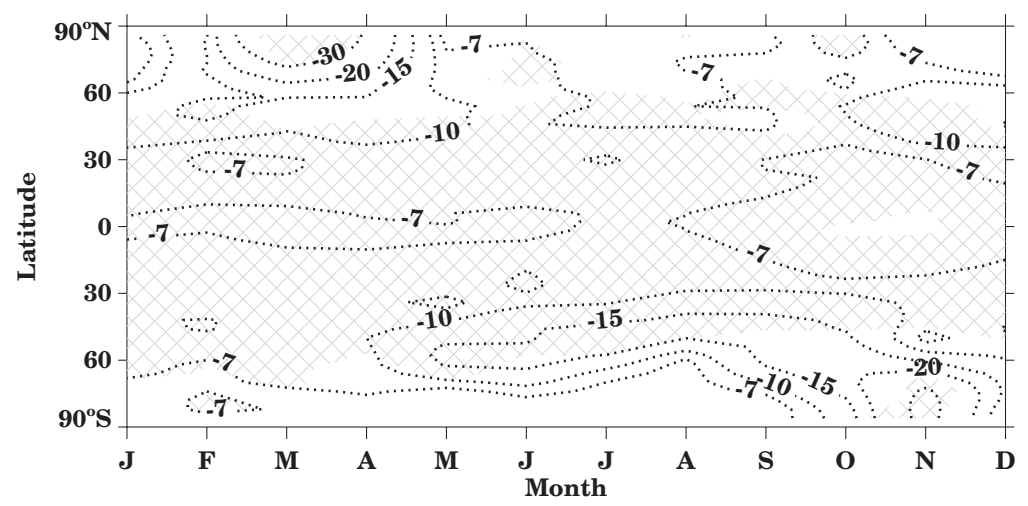

Figure 3. Zonal mean difference (DU) of the future total column ozone between APS (anthropogenic and solar forcing) and ANT (anthropogenic forcing) runs. Hatching represent the areas where the statistical significance exceed $90 \%$ level. 

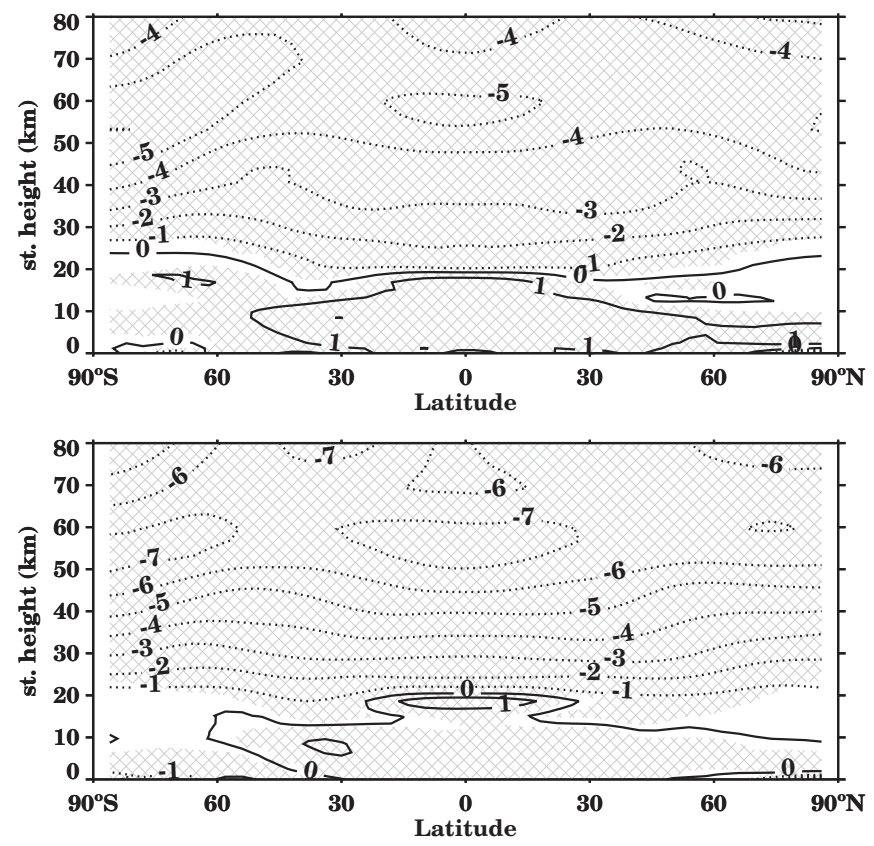

Figure 4. Annual and zonal mean difference $(\mathrm{K})$ of the temprature in the future relative to present for ANT (anthropogenic forcing, upper panel) and APS (anthropogenic and solar forcing, lower panel) runs. Hatching represent the areas where the statistical significance exceed $90 \%$ level.

temperature change in the future relative to present for ANT and APS runs is illustrated in Fig. 4. The projected increase of greenhouse gas emissions leads to the pronounced cooling in the entire stratosphere reaching $5 \mathrm{~K}$ near the stratopause. The ozone recovery (see Fig. 2) caused by smaller halogen loading in the future atmosphere partially compensate the cooling due to greenhouse gases. The compensation is almost complete in the polar lower stratosphere, where the ozone recovery is the most remarkable. The increase of downward infrared radiation caused by greenhouse gases produces tropospheric warming exceeding $1 \mathrm{~K}$. The solar influence slightly alters the pattern of the temperature response. Substantial drop of solar UV irradiance leads to decrease of radiative heating, ozone concentration and additional (up to $2 \mathrm{~K}$ ) cooling in the stratosphere. The ozone increase in the polar mesosphere (see Fig. 2) caused by lower geomagnetic activity slightly compensates the cooling there, but cannot compete with the effects of solar UV irradiance. The introduced reduction of TSI affects surface energy budget and leads to global mean cooling at the surface by about $0.5 \mathrm{~K}$ followed by tropospheric cooling with about the same magnitude. The geographical distribution of the annual mean solar contribution to the 2 meter temperature over the land masses is illustrated in Fig. 5, which shows that the solar contribution is statistically significant almost everywhere and not homogeneously distributed. The most pronounced cooling (up to $1.2 \mathrm{~K}$ ) appears over India, Central Asia, Siberia and Antarctica. The cooling over the other geographical regions is in the range from 0.5 to $0.7 \mathrm{~K}$. This space inhomogeneity can be explained by the influence of the other introduced solar forcing mechanisms (solar UV irradiance and energetic particles) which cannot affect global mean temperature but are able to redistribute the pattern of surface temperature response (Egorova et al. 2004; Calisto et al. 2011). The comparison of the temperature changes in the future for ANT and APS runs shows that the solar forcing can compensate about $50 \%$ of the climate warming due to 


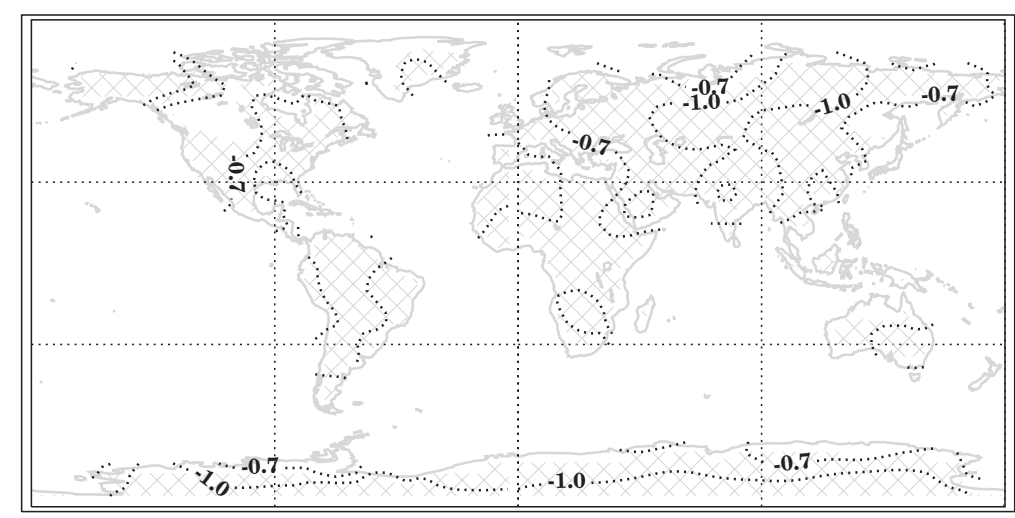

Figure 5. Annual mean difference $(\mathrm{K})$ of the future 2 meters temperature between APS (anthropogenic and solar forcing) and ANT (anthropogenic forcing) runs. Hatching represent the areas where the statistical significance exceed $90 \%$ level.

pure anthropogenic factors, while in some geographical locations solar forcing can even dominate.

\section{Summary}

We have simulated the present and future climate and atmospheric state using CCM SOCOL v2.0 in time slice mode. To estimate the consequences of a potential strong decrease of the solar activity we simulated the future using pure anthropogenic forcing as well as in combination with different solar activity related factors. We have taken into account possible changes of the total solar irradiance, spectral solar irradiance, energetic electron precipitation, solar protons and galactic cosmic rays suggesting that the solar activity will become similar to the Dalton minimum around year 2050. The comparison of the model simulations shows that introduced strong decrease of solar activity can lead to some delay of the ozone recovery and partially compensate greenhouse warming acting in the direction opposite to anthropogenic effects. On the other hand, the anthropogenically induced cooling in the stratosphere is enhanced by solar forcing. The model results also show that all considered solar forcings are important in different atmospheric layers and geographical regions; however, the solar irradiance variability can be considered as the most important for global problems. The obtained results constitute probably the upper limit of the possible solar influence. Deeper understanding and construction of better constrained set of future solar forcings is necessary to address the problem of future climate and ozone layer state with more confidence. The development of more reliable solar forcing data sets requires in turn maintaining and extending of all relevant satellite and ground based observations as well as further theoretical investigations.

\section{Acknowledgements}

The research leading to this paper was partially supported by the Swiss National Science Foundation under grant CRSI122-130642 (FUPSOL).

\section{References}

Abreu, J., Beer, J., Steinhilber, F., Tobias S., \& Weiss, N. 2008, Geophys. Res. Lett., 35, L20109 Barnard, L., Lockwood M., Hapgood, M., Owens, M., Davis, C., \& Steinhilber, F. 2011, Geophys. Res. Lett., 38, L16103 
Baumgaertner, A., Jöckel, P., \& Brühl, C. 2009, Atmos. Chem. Phys., 9, 2729

Calisto, M., Usoskin, I., Rozanov, E., \& Peter, T. 2011, Atmos. Chem. Phys., 11, 4547

Egorova, T., Rozanov, E., Zubov, V., \& Karol, I. 2003, Izvestiya, Atmospheric and Oceanic Physics, 39, 277

Egorova, T., Rozanov, E., Manzini, E. et al. 2004, Geophys. Res Lett., 31, L06119

Egorova, T., Rozanov, E., Zubov, V., Manzini, E., Schmutz, W., \& Peter, T 2005, Atmos. Chem. Phys., 5, 1557

Egorova, T., Rozanov, E., Ozolin, Y., Shapiro, A. V., Peter, T., \& Schmutz, W. 2011, Journal of Atmospheric and Solar-Terrestrial Physics, 73, 356

Eyring, V., Waugh, D. W., Bodeker, G. et al. 2007, J. Geophys. Res., 112, D16303

Feulner, G. 2011, Geophys. Res. Lett., 38, L16706

Gray, L., Beer, J., Geller, M. et al. 2010, Rev. Geophys., 48, RG4001

IPCC: Intergovernmental Panel on Climate Change 2007, Cambridge University Press, 489

Jackman, C., Marsh, D., Vitt, F. et al. 2008, Atmos. Chem. Phys., 8, 765

Lockwood, M., Rouillard, A., \& Finch, I. 2009, Astrophys. J., 70, 937

Manzini, E., McFarlane, N. A., \& McLandress, C. 1997, J. Geophys. Res., 102, 25751

Morgenstern, O., Giorgetta, M. A., Shibata, K., et al. 2010, J. Geophys. Res., 115, D00M02

Porter, H., Jackman, C., \& Green, A. 1976, J. Chem. Phys., 65, 154

Rozanov, E., Callis, L., Schlesinger, M., Yang, F., Andronova, N., \& Zubov, V. 2005, Geophys. Res. Lett., 32, L14811

Shapiro, A. I., Schmutz, W., Rozanov, E., Schoell, M., Haberreiter, M, Shapiro, A. V., \& Nyeki, S. 2011, Astron. Astrophys., 539, A67

Schraner, M., Rozanov, E., Schnadt Poberaj, C. et al. 2008, Atmos. Chem. Phys., 8, 5957

Semeniuk, K., Fomichev, V., McConnell, J., Fu, C., Melo, S., \& Usoskin, I. 2011, Atmos. Chem. Phys., 11, 5045

Sinnhuber, M., Kazeminejad, S., \& Wissing J. M. 2011, J. Geophys. Res., 116, A02312

Schrijver, C.,Livingston, W., Woods, T., \& Mewaldt, R. 2011, Geophys. Res. Lett., 38, L06701

Solomon, S., Rusch, D., Gerard, J., Reid, G., \& Crutzen, P. 1981, Planetary Space Science, 29, 885

SPARC CCMVal: Eyring, V., Shepherd, T., \& Waugh, D. (eds) 2010, WCRP-132/WMO/TD$1526 / S P A R C, 5$

Steinhilber, F., Abreu, J., Beer, J., \& McCracken, K. 2010, J. Geophys. Res., 115, A01104

Stott, P., Jones, G., \& Mitchell, J. 2003, J. Clim., 16, 4079

Usoskin, I., Kovaltsov, G., \& Mironova, I. 2010, J. Geophys. Res., 115, D10302

Usoskin, I. \& Kovaltsov, G. 2006, J. Geophys. Res., 111, D21206

WMO (World Meteorological Organization): Scientific Assessment of Ozone Depletion: 2010. 2011, Global Ozone Reaserch and Monitoring Project Report No 52, 516

\section{Discussion}

LeIF SvaAlgard: Cosmic rays and clouds. Some believe in this effect some not. Is that included in your model?

Eugene Rozanov: This effect is not included in the model, because we do not have physically based parameterization to do it.

Axel Brandenberg: It is not true that there is no data on cosmic rays influence on clouds. There are lab experiments and mechanisms that have been developed for the effects of cosmic rays forcing.

Eugene Rozanov: There are some data and mechanisms, but it is not enough to properly include them in the model. Physically based parameterizations are still not available.

ERIC PRIEst: How important is UV variability? 
Eugene Rozanov: It is very important. It explains most of the ozone changes and nonhomogeneity of the surface air temperature response. The change of TSI gives rather homogeneous pattern of the temperature response. For example, the band of cooling over the Russia is formed by UV changes.

JANET LUHMANN: Will the polar ice change affect the results of your model?

Eugene Rozanov: Yes. The model I used here has simplified representation of the see ice. Better representation of the see ice is necessary. Similar experiments are on-going with more complicated version of the model.

MARK GIAMPAPA: What are the errors in your estimates from your model?

Eugene RozAnov: The results inside hatched areas are statistically significance at more than $90 \%$ level. The uncertainties depend on the accuracy of the forcing projections, which can hardly be estimated.

LeIf SvaAlgard: Before the Dalton minimum and other similar periods there were several volcanic eruptions, which could produce colder climate. Why not use volcanic forcing for the future runs?

Eugene Rozanov: We tried to estimate possible compensation of greenhouse effect and ozone recovery by solar influence. Volcanic forcing is important for the prediction of future climate, but this question is out of scope of this particular work.

Not IDENTIFIED WOMAn: I would urge you to consider volcanic eruptions in your simulation of the future climate.

Eugene Rozanov: There is no reliable scenario for future volcanic eruption frequency and strength. Anyway, if there is enhanced volcanic activity in the future, the compensation of the greenhouse warming and ozone recovery will be also enhanced. 